\title{
Torque Performance and Permanent Magnet Arrangement for Interior Permanent Magnet Synchronous Motor
}

\author{
Naohisa Matsumoto Student Member (Osaka Prefecture University, matumoto@eis.osakafu-u.ac.jp) \\ Masayuki Sanada Member (Osaka Prefecture University, sanada@eis.osakafu-u.ac.jp) \\ Shigeo Morimoto Member (Osaka Prefecture University, morimoto@eis.osakafu-u.ac.jp) \\ Yoji Takeda Member (Osaka Prefecture University, takeda@eis.osakafu-u.ac.jp)
}

Keywords: interior permanent magnet synchronous motor, torque performances, permanent magnet arrangement, flux barrier, reluctance torque, magnet torque, finite element method

An interior permanent magnet synchronous motor (IPMSM) has many advantages, such as high efficiency and excellent torque performance, so it is widely used in the industrial field.

In an IPMSM using the rare earth permanent magnet (PM), typically the magnet is deeply embedded in the rotor and the flux barrier of one magnet is adjacent to the flux barrier of the next magnet. However, the embedded depth of the permanent magnet and the shape of the flux barriers have a large influence on torque performances, so it is necessary to reexamine them. This paper describes the relation between the permanent magnet arrangement and torque performances for a single-layer IPMSM using the rare earth permanent magnet.

The models were analyzed by the finite element method. The standard model of the IPMSM using the rare earth permanent magnet is shown in Fig. 1(a). In this paper, this model is called Type A.

First, the models which changed the embedded depth of the permanent magnets are analyzed. A example of the analytical models is shown in Fig. 1(b). The size of the permanent magnets $(3.0 \mathrm{~mm})$ and the thickness of the flux barriers $(2.1 \mathrm{~mm})$ are the same in the models. The analytical results show that the armature flux linkage due to the permanent magnet $\psi_{a}$ increases and the magnet torque $T_{m}$ also increases as the permanent magnets are moved toward the surface. When the permanent magnets are moved toward the surface, the cross-sectional area of the flux barriers decreases and the leakage of the magnetic flux inside the rotor decreases.

Second, the models in which the thickness of the flux barriers is expanded are analyzed. The analytical results show that $\psi_{a}$ and the magnet torque $T_{m}$ increase as the thickness of the flux barriers increases in comparison with Type A. The magnetic flux coming out from the permanent magnets is almost equal in each model. So, it is confirmed that the increase of $\psi_{a}$ is the leakage of the magnetic flux in the flux barriers.

Third, the models which changed the shape of the flux barriers are analyzed. A example of the analytical models is shown in Fig. 2(b). The analytical results show that the torque ripple characteristic is significantly improved by using the asymmetrical flux barriers without sacrificing the average torque.

Next, The prototype motors of Type A and Type $\mathrm{C}$ were manufactured. The line-to-line induced voltage of Type $\mathrm{C}$ is about $30 \%$ larger than that of Type A. Since the induced voltage is proportional to the armature flux linkage due to the permanent magnet $\psi_{a}$, the increase of $\psi_{a}$, which is shown by the analysis, is confirmed.

As a result, It turns out that the magnet torque increases as the permanent magnets are moved to the surface. This was confirmed in the experiment. The torque increases when the permanent magnet is moved toward the surface because the leakage of the magnetic flux decreases. In addition, the torque ripple is significantly improved when using the asymmetrical flux barriers.

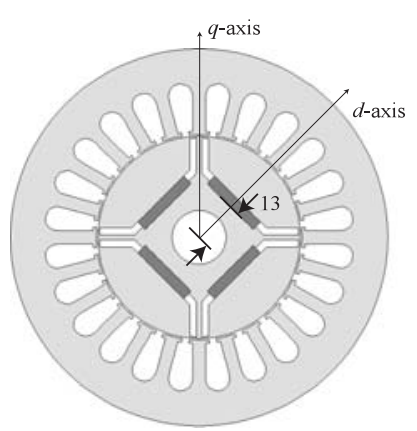

(a) Type $\mathrm{A}$

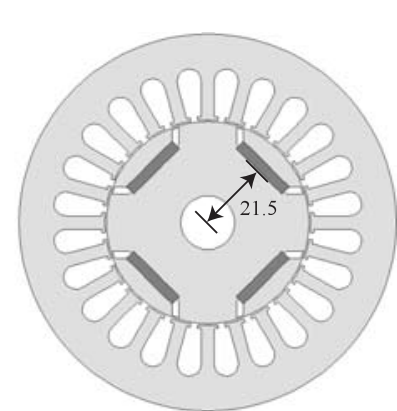

(b) Type C

Fig. 1. Various rotors of IPMSM

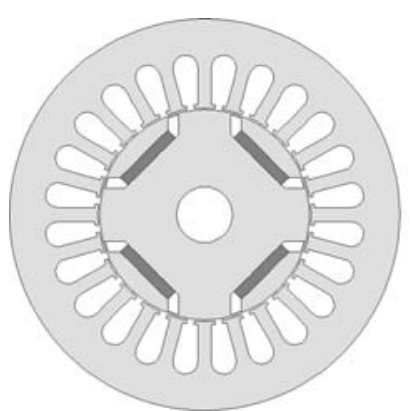

(a) Type I (Type $\mathrm{C}^{\prime}$ )

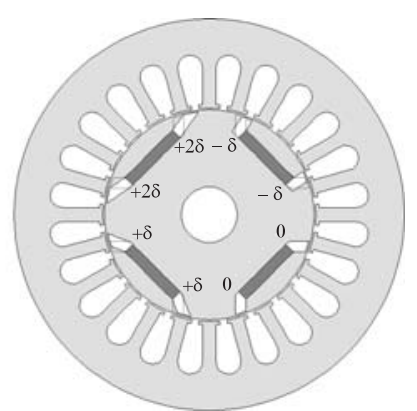

(b) Type II

Fig. 2. Asymmetrical flux barrier models 


\title{
Torque Performance and Permanent Magnet Arrangement for Interior Permanent Magnet Synchronous Motor
}

\author{
Naohisa Matsumoto* Student Member \\ Masayuki Sanada* Member \\ Shigeo Morimoto* \\ Yoji Takeda* \\ Senior Member \\ Senior Member
}

The use of the interior permanent magnet synchronous motor (IPMSM) has increased in the industrial field because of its excellent characteristics, such as high efficiency, wide range of speed operation and flexibility of the rotor structure. Therefore, the IPMSM, especially one using the rare earth permanent magnet, is being actively studied.

In the IPMSM using the rare earth permanent magnet, typically the permanent magnet is deeply embedded in the rotor. However, torque performances are significantly influenced by the rotor structures. This paper describes the torque performances for a single-layer IPMSM using the rare earth permanent magnet when the permanent magnet arrangements are changed.

Keywords: interior permanent magnet synchronous motor, torque performances, permanent magnet arrangement, flux barrier, reluctance torque, magnet torque, finite element method

\section{Introduction}

An interior permanent magnet synchronous motor (IPMSM) has many advantages, such as high efficiency and excellent torque performance, so it is widely used in the industrial field.

In an IPMSM using the rare earth permanent magnet (PM), typically the magnet is deeply embedded in the rotor and the flux barrier of one magnet is adjacent to the flux barrier of the next magnet. However, the embedded depth of the permanent magnet and the shape of the flux barriers have a large influence on torque performances, so it is necessary to reexamine them ${ }^{(1)-(4)}$. This paper describes the relation between the permanent magnet arrangement and torque performances for a single-layer IPMSM using the rare earth permanent magnet.

\section{Basic Equation and Construction of the IPMSM}

The basic torque equation of the IPMSM is shown in (1).

$$
T=P_{n} \psi_{a} i_{q}+P_{n}\left(L_{d}-L_{q}\right) i_{d} i_{q}
$$

where $P_{n}$ is the number of pole pairs, $\psi_{a}$ is the armature flux linkage due to permanent magnets, $i_{d}$ is the $d$-axis current, $i_{q}$ is the $q$-axis current, $L_{q}$ is the $q$-axis inductance and $L_{d}$ is the $d$-axis inductance. The 1 st term of the right-hand side is the magnet torque component $T_{m}$, and the 2 nd term is the reluctance torque component $T_{r}$. To enlarge the average torque $T$, it is necessary to make either the armature flux linkage due to $\operatorname{PM} \psi_{a}$ or $\left(L_{q}-L_{d}\right)$ a large value.

Moreover, Equation (1) is transformed into (2) when $I_{a}$ $\left(=\sqrt{i_{d}^{2}+i_{q}^{2}}=\sqrt{3} I_{e}\right)$ and the leading phase angle $\beta$ from * Osaka Prefecture University

1-1, Gakuen-cho, Sakai, Osaka 599-8531, JAPAN $q$-axis are used.

$$
T=P_{n} \psi_{a} I_{a} \cos \beta+\frac{1}{2} P_{n}\left(L_{q}-L_{d}\right) I_{a}^{2} \sin 2 \beta \ldots \ldots \ldots
$$

As shown in (2), the magnet torque component $T_{m}$ is proportional to $I_{a}$ and the reluctance torque component $T_{r}$ is proportional to $I_{a}^{2}$. Therefore, when changing $I_{a}$, the magnet torque ratio and the reluctance torque ratio of the total torque also change. So, the rotor structure which produces the maximum torque may be changed by the phase current of $I_{e}$.

The IPMSM rotor is classified into two basic structures, as shown in Fig. 1. The type shown in Fig. 1(a) is generally used in an IPMSM using the rare earth permanent magnet. The high-performance permanent magnet is deeply embedded in the rotor so that it needs a wider space for the $q$-axis flux. On the other hand, the type shown in Fig. 1(b) is generally used in an IPMSM using a relatively low performance permanent magnet such as ferrite. When using the low performance permanent magnet, it is necessary to enlarge the thickness of the permanent magnets. In this case the magnets

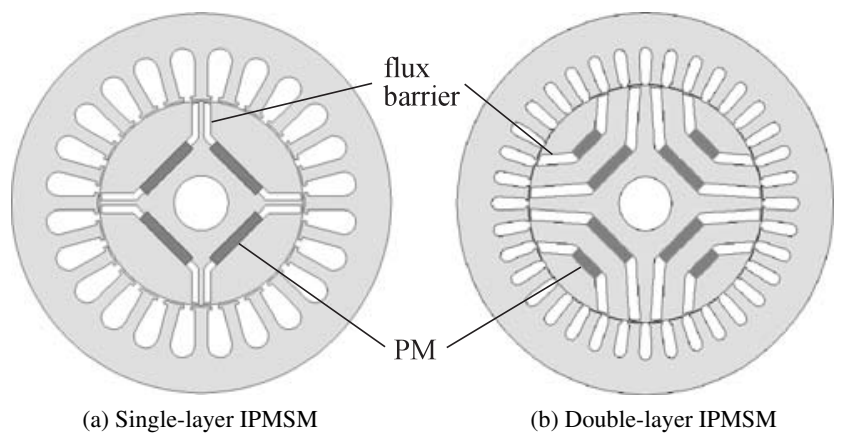

Fig. 1. Two types of IPMSM 
are embedded by dividing the rotor into two layers so that more $q$-axis armature flux can pass through the rotor. In this paper, the single-layer IPMSM is examined. Compared with the two-layer IPMSM, it excels at the mechanical strength and the productivity because of its simple structure.

\section{Embedded Depth of the PM and the Torque Characteristic}

3.1 Analytical Models The models are analyzed by the 2D nonlinear finite element method. The number of elements is about 20,000 . The models are comparatively lightly saturated. The inductance $L_{d}$ and $L_{q}$ are calculated by the armature flux linkage and $\psi_{a}$ using vector diagram. The uphase armature flux linkage is calculated at the center of slots.

The standard model of the IPMSM using the rare earth permanent magnet is shown in Fig. 2(a). In this paper, this model is called Type A. The specifications of Type A, which are common to all the analytical models, are shown in Table 1.

The four analytical models are shown in Fig. 2. The size

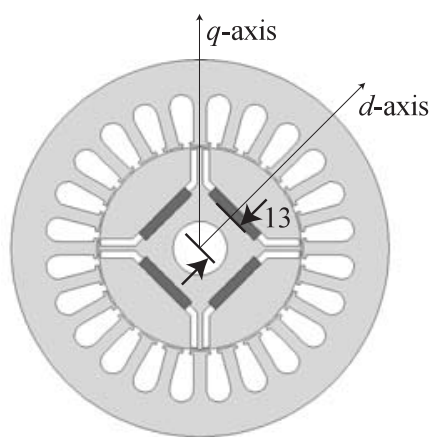

(a) Type A

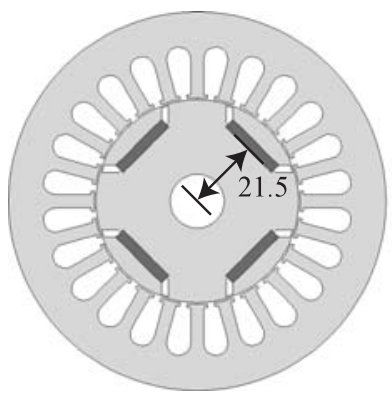

(c) Type $\mathrm{C}$

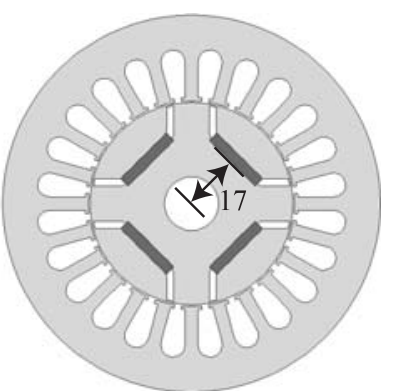

(b) Type B

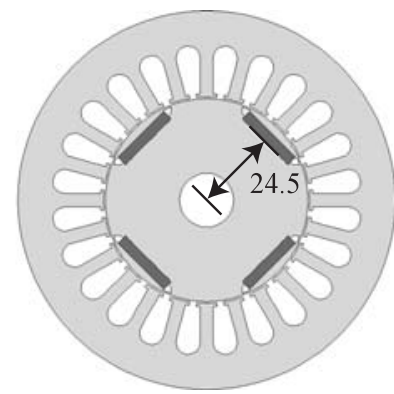

(d) Type D
Fig. 2. Various rotors of IPMSM

Table 1. Specifications of analytical models

\begin{tabular}{r|r}
\hline \multicolumn{1}{c|}{ Item } & \multicolumn{1}{|c}{ Value } \\
\hline Number of slots & 24 \\
Number of turns per slot & 58 \\
Stack length & $40 \mathrm{~mm}$ \\
Stator diameter & $112 \mathrm{~mm}$ \\
Rotor diameter & $60 \mathrm{~mm}$ \\
Shaft diameter & $16 \mathrm{~mm}$ \\
Bridge length & $0.5 \mathrm{~mm}$ \\
Airgap length & $0.5 \mathrm{~mm}$ \\
Thickness of PM & $3.0 \mathrm{~mm}$ \\
Width of PM & $19 \mathrm{~mm}$ \\
Coercive force of PM & $915 \mathrm{kA} / \mathrm{m}$ \\
Rated current $I_{e}$ & $3.0 \mathrm{~A}$ \\
\hline
\end{tabular}

of the permanent magnets $(3.0 \mathrm{~mm})$ and the thickness of the flux barriers $(2.1 \mathrm{~mm})$ are the same in all the models. Also, the direction of the flux barriers is parallel to that of the $q$ axis in all the models. In Type B, Type C, and Type D, the space between the two adjacent flux barriers is expanded and the permanent magnets are shallowly embedded in comparison with Type A. In Type D, the magnets are embedded near the surface of the rotor. The distance from the center of the rotor to the magnets is $13 \mathrm{~mm}$ in Type A, $17 \mathrm{~mm}$ in Type B, $21.5 \mathrm{~mm}$ in Type $\mathrm{C}$ and $24.5 \mathrm{~mm}$ in Type D.

3.2 Analytical Results The inductance characteristic is shown in Fig. 3, the armature flux linkage due to the PM is shown in Fig. 4, the average torque is shown in Fig. 5, and the torque ripple is shown in Fig. 6. The torque ripple is defined as the variation of the instantaneous torque divided by the average torque. All results are obtained at the maximum torque control, and the current phase is 30 degrees.

In Type B and Type C, the space between the two adjacent flux barriers is wide compared with Type A, so the $q$-axis inductance $L_{q}$ increases as shown in Fig. 3. In Type A, the $q$-axis flux mainly passes between the permanent magnet and the surface of the rotor. But in Type B and Type C, the $q$-axis flux passes through not only the above mentioned path but also the space between the two flux barriers. In Type D, although the space between the flux barriers is wide, the $q$-axis flux passageway between the permanent magnets and the surface of the rotor is narrow. Therefore, $L_{q}$ of Type $\mathrm{D}$ is smaller than that of Type B and Type C.

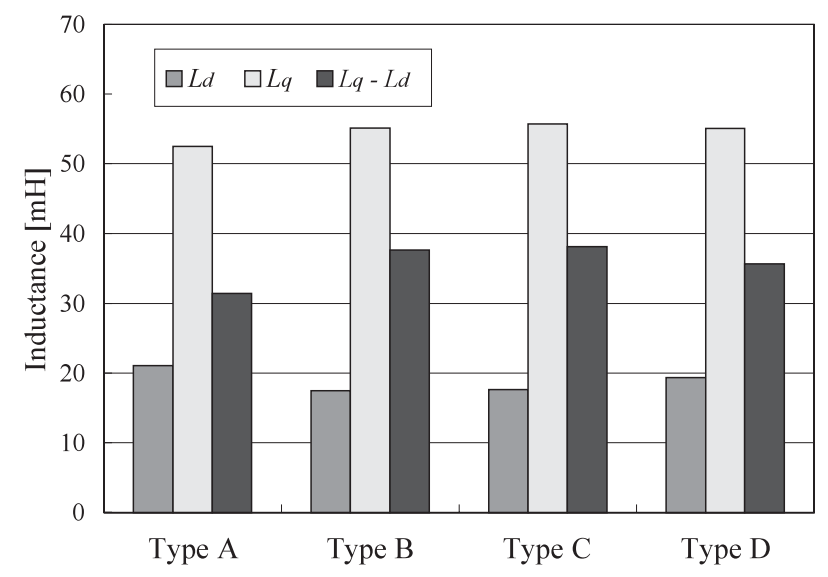

Fig. 3. Inductance characteristics

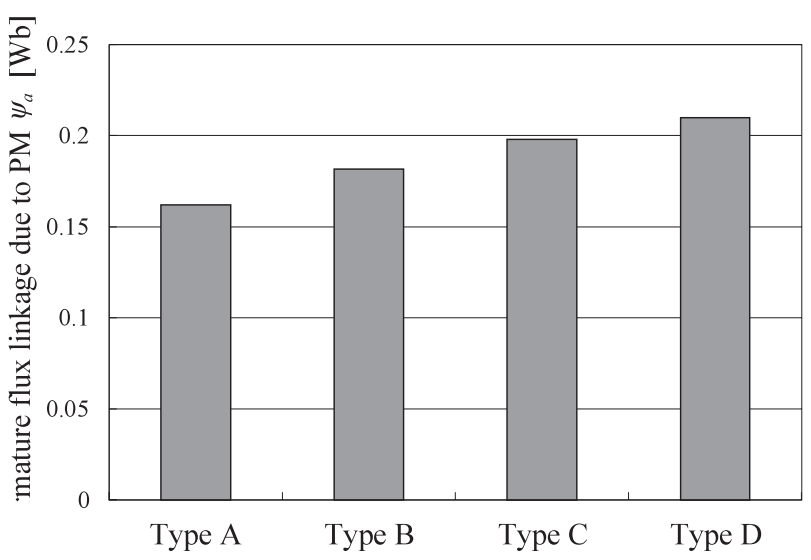

Fig. 4. Armature flux linkage due to PM 


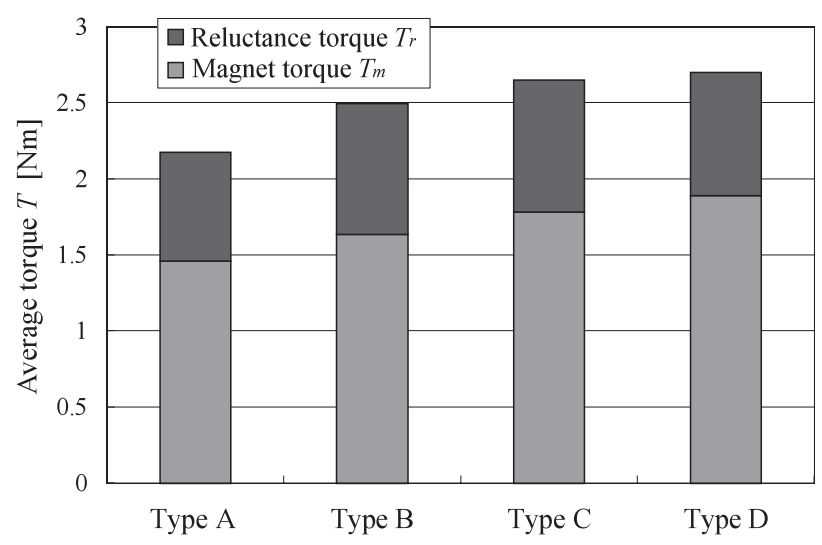

Fig. 5. Torque performance

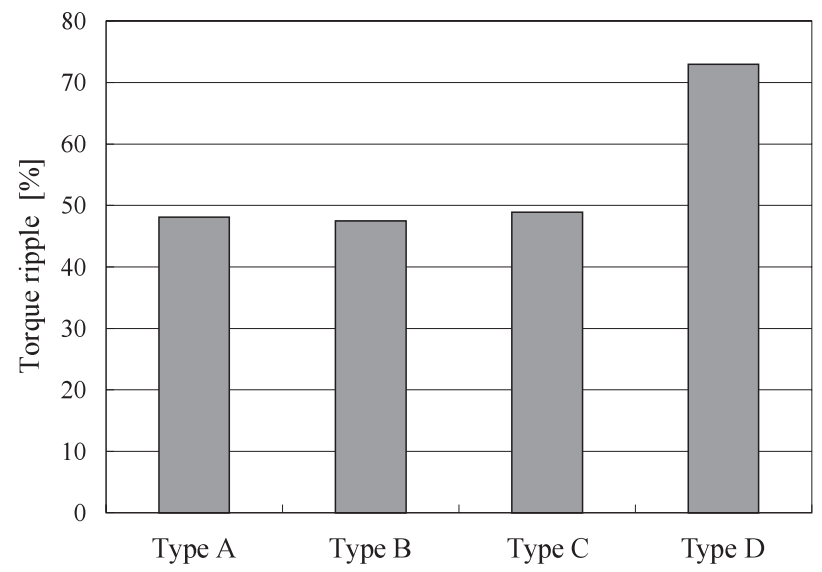

Fig. 6. Torque ripple characteristic

In Type $\mathrm{B}$ and Type $\mathrm{C}$ the $d$-axis inductance $L_{d}$ slightly decreases compared with Type A because the length of the flux barrier becomes short and the $d$-axis flux which passes through the flux barrier decreases. $L_{d}$ of Type D is larger than that of Type B and Type $\mathrm{C}$ because the space between the two adjacent flux barriers becomes large and the $d$-axis flux which doesn't passes through the flux barrier increases. As mentioned above, $\left(L_{q}-L_{d}\right)$ of Type B and Type $\mathrm{C}$ is large compared with that of Type A, so the reluctance torque $T_{r}$ of Type B and Type $\mathrm{C}$ slightly increases compared with Type A.

On the other hand, Fig. 4 shows that the armature flux linkage due to the permanent magnet $\psi_{a}$ increases and the magnet torque $T_{m}$ also increases as the permanent magnets are moved toward the surface. In Type $\mathrm{D}, \psi_{a}$ is about $30 \%$ more than Type A. When the permanent magnets are moved toward the surface, the cross-sectional area of the flux barriers decreases and the leakage of the magnetic flux inside the rotor decreases.

The average torque of Type $\mathrm{D}$ is the largest of the four models. But, the torque ripple of Type D is much larger than the other models, as shown in Fig. 6. Therefore, it turns out that the proper rotor structure in these analytical models is Type $\mathrm{C}$ from the viewpoints of torque performance and torque ripple characteristic.

\section{Thickness of the Flux Barriers and the Torque Characteristic}

4.1 Analytical Models In this section the relation

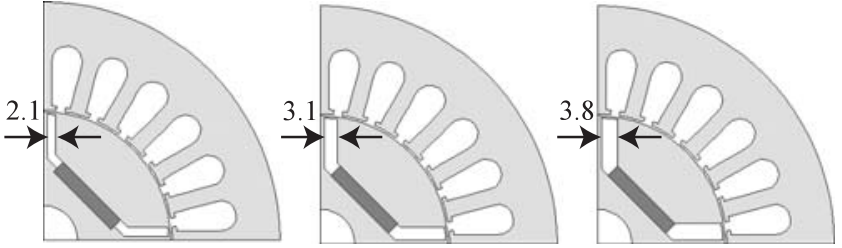

(a) Type A

(b) Type $\mathrm{A}^{\prime}$

(c) Type $\mathrm{A}^{\prime \prime}$

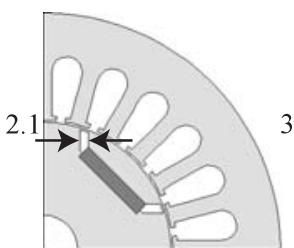

(d) Type C

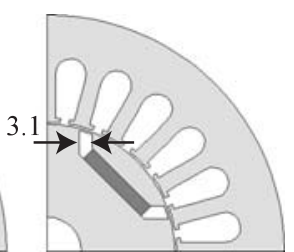

(e) Type $\mathrm{C}^{\prime}$
Fig. 7. Expanded flux barrier models

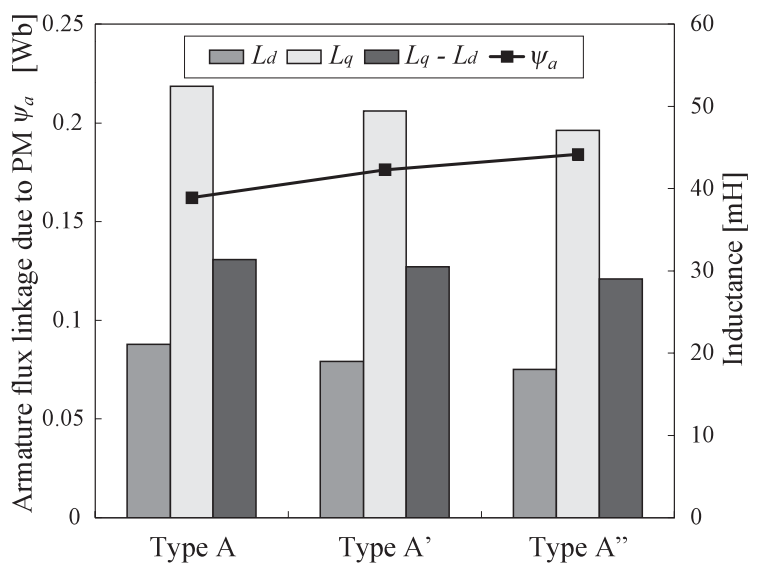

Fig. 8. Inductance and $\psi_{a}$ characteristic

between the magnetic resistance $R$ of the flux barriers and torque performances is examined. The equation of the magnetic resistance of a flux barrier is shown in (3).

$$
R=\frac{w}{\mu_{0}(d l)}
$$

where $w$ is the thickness of the flux barrier, $d$ is the length of the flux barrier, $l$ is the stack length and $(d l)$ is the crosssectional area of the flux barrier.

The leakage of the magnetic flux inside the rotor decreases as the magnetic resistance $R$ increases. As shown in (3), to make the magnetic resistance larger, it is necessary to make the thickness $w$ of a flux barrier larger or to make the length $d$ of a flux barrier shorter. So, the models in which the thickness of the flux barriers is expanded, as shown in Fig. 7, are analyzed. The thickness of the flux barriers is $2.1 \mathrm{~mm}$ in Type A, $3.1 \mathrm{~mm}$ in Type $\mathrm{A}^{\prime}, 3.8 \mathrm{~mm}$ in Type $\mathrm{A}^{\prime \prime}, 2.1 \mathrm{~mm}$ in Type $\mathrm{C}$ and $3.1 \mathrm{~mm}$ in Type $\mathrm{C}^{\prime}$.

4.2 Analytical Results The inductance characteristic and the armature flux linkage due to the PM are shown in Fig. 8, and the average torque and the torque ripple are shown in Fig. 9 and Fig. 10, respectively. The average flux density in the permanent magnets is shown in Fig. 11.

Fig. 8 and Fig. 9 show that $\psi_{a}$ and the magnet torque $T_{m}$ increase as the thickness of the flux barriers increases in comparison with Type A. The magnetic flux coming out from the permanent magnets is almost equal in each model, as shown 
in Fig. 11. So, it is confirmed that the increase of $\psi_{a}$ is the leakage of the magnetic flux in the flux barriers.

Although the increase of the thickness of the flux barriers leads to the increase of the magnet torque $T_{m}$, as shown in Fig. 9, the reluctant torque $T_{r}$ scarcely decreases because the increase of the thickness of the flux barriers leads to the decrease of the $q$-axis flux passageway. In addition, the increase of the thickness of the flux barriers causes the increase of the torque ripple, as shown in Fig. 10. Moreover when the flux barriers are expanded too much, the bridge part becomes wide and the mechanical strength becomes weak. Therefore, it turns out that there is an optimal value for the thickness of the flux barriers.

Also, the torque ripple of each model is large, as shown

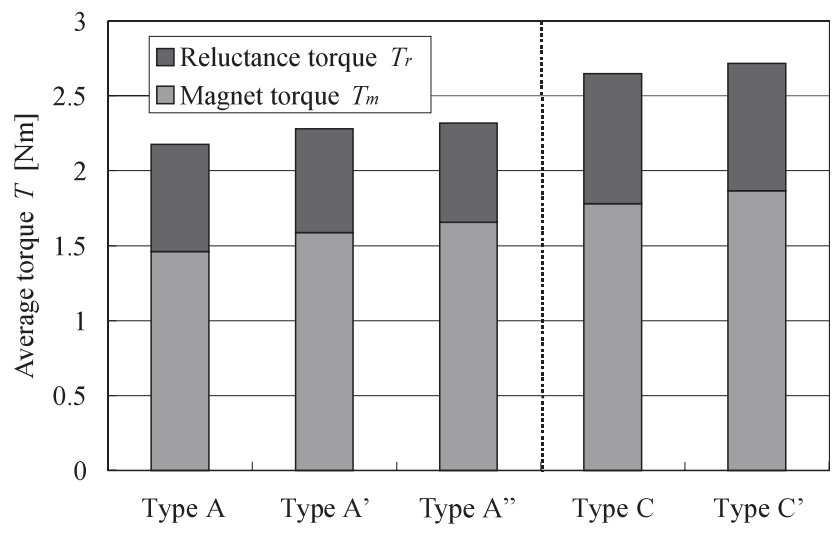

Fig. 9. Torque performance

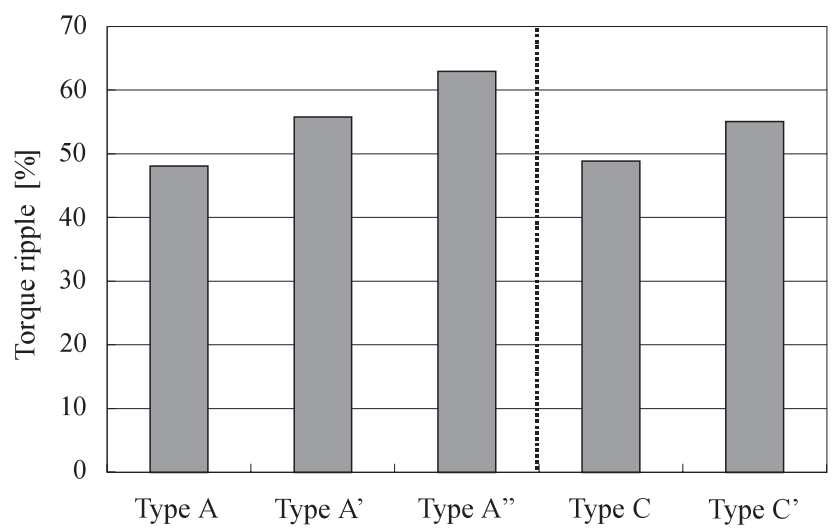

Fig. 10. Torque ripple characteristic

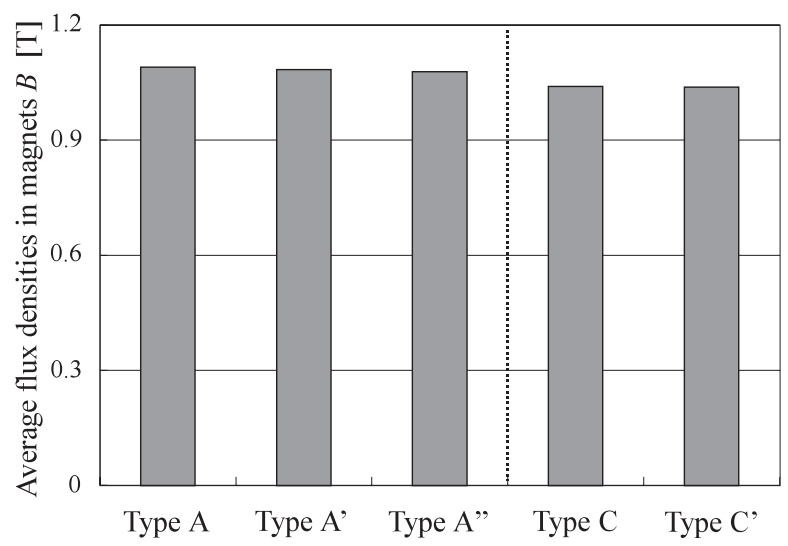

Fig. 11. Average flux densities in magnets in Fig. 6 and Fig. 10. The torque ripple can be reduced by designing asymmetrical flux barriers ${ }^{(5)(6)}$.

\section{Torque Ripple Improvement}

5.1 Shape of the Flux Barriers The instantaneous torque of an IPMSM is significantly influenced by the position between the flux barriers and the teeth. Type I, which is called Type $\mathrm{C}^{\prime}$ in the previous chapter, is the standard model in this section. In Type I, the flux barriers at both ends of the permanent magnets are the same shape, as shown in Fig. 12(a). It is thought that the torque ripple is reduced when the relative position between a flux barrier and the teeth is broken up individually. Although in (5) and (6) only the models which has the same flux barriers at both ends of one permanent magnet are examined, in this paper various combinations of the flux barrier arrangement are examined.

5.2 Analytical Models The angle of the flux barriers in Type $\mathrm{I}$ is defined as 0 degrees, and the criterion of the bending angles is the $\delta$ shown in (4).

$$
\delta=\tau_{s} / P
$$

where $\tau_{s}$ is the slot pitch angle and $P$ is the number of poles. In this case $\delta$ is $3.75(=15 / 4)$ degrees. The flux barrier arrangement of the analytical models is shown in Table 2, and Type I and Type II are shown in Fig. 12. In Table 2, a flux barrier is bent more toward the inside when the sign is positive and more toward the outside when the sign is negative, when compared with Type I. The bending angle increases as the absolute value becomes larger. The number in Table 2 indicates how many of the same forms of the flux barriers there are in each model. In addition, when the number is 2 , the same flux barriers are arranged at both ends of one permanent magnet. In Fig. 12(b), the shape of the flux barrier of Type I is shown as a dotted line and the bending angles of the flux barriers are also shown near the flux barriers.

\subsection{Analytical Results The average torque at the}

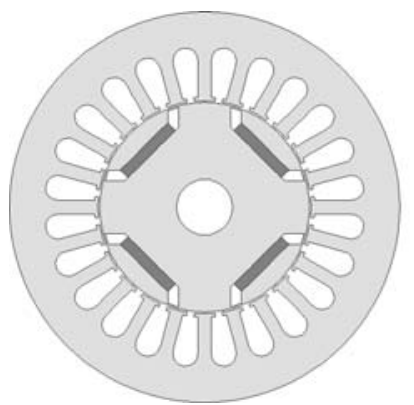

(a) Type I (Type $\mathrm{C}^{\prime}$ )

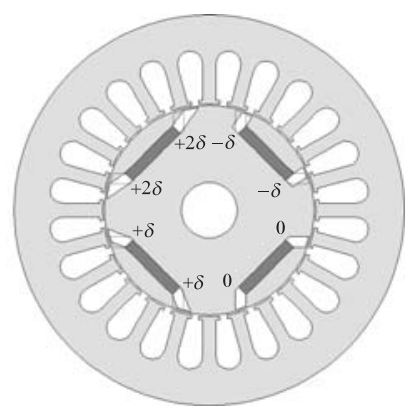

(b) Type II
Fig. 12. Asymmetrical flux barrier models

Table 2. Flux barrier arrangement of analytical models

\begin{tabular}{l|r|r|r|r|r|r|r|r}
\hline & \multicolumn{1}{|c|}{$-\delta$} & $-1 / 2 \delta$ & \multicolumn{1}{c|}{0} & $1 / 2 \delta$ & $\delta$ & $3 / 2 \delta$ & $2 \delta$ & $5 / 2 \delta$ \\
\hline Type I & & & 8 & & & & & \\
\hline Type II & 2 & & 2 & & 2 & & 2 & \\
\hline Type III & & 2 & & 2 & & 2 & & 2 \\
\hline Type IV & 2 & 2 & 2 & 2 & & & & \\
\hline Type V & & 2 & 2 & 2 & 2 & & & \\
\hline Type VI & 1 & 1 & 1 & 1 & 1 & 1 & 1 & 1 \\
\hline
\end{tabular}


maximum torque control is shown in Fig. 13, and the torque ripple and the instantaneous torque waveform are shown in Fig. 14 and Fig. 15, respectively. Fig. 13 shows that the average torque scarcely changes when the bending angle of the flux barriers is changed.

Moreover, it turns out that the torque ripple of Type II and Type VI is small, as shown in Fig. 14. The instantaneous torque waveforms of Type II and Type VI are smooth compared with that of Type I, as shown in Fig. 15. By the way, to maintain the dynamic balance it is necessary to laminate the silicon steel plate, rotating it clockwise or counterclockwise. In Type II the dynamic balance is maintained by laminating

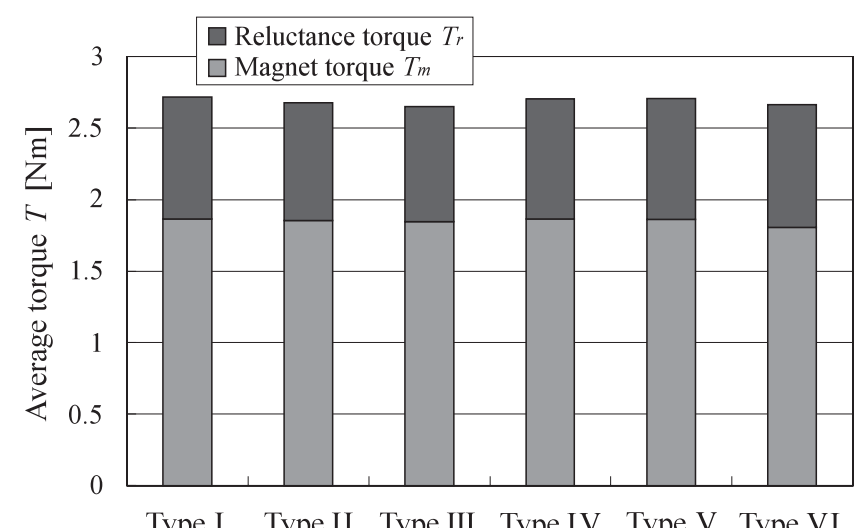

Fig. 13. Torque performance

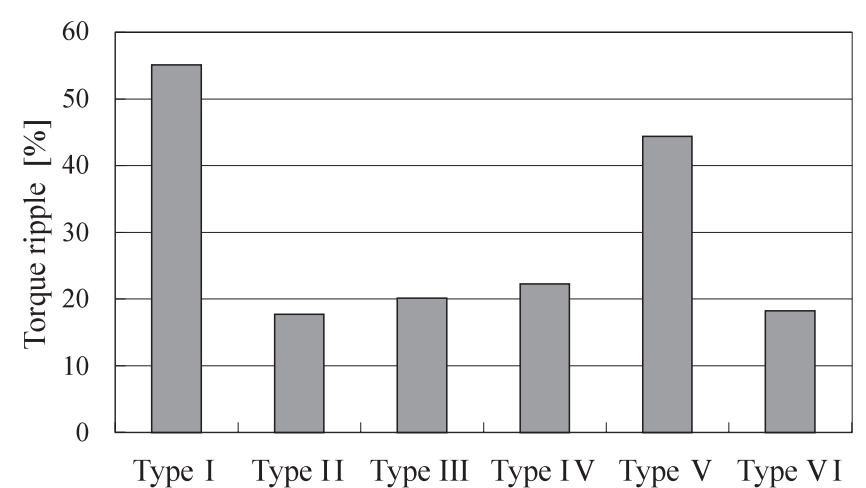

Fig. 14. Torque ripple characteristic

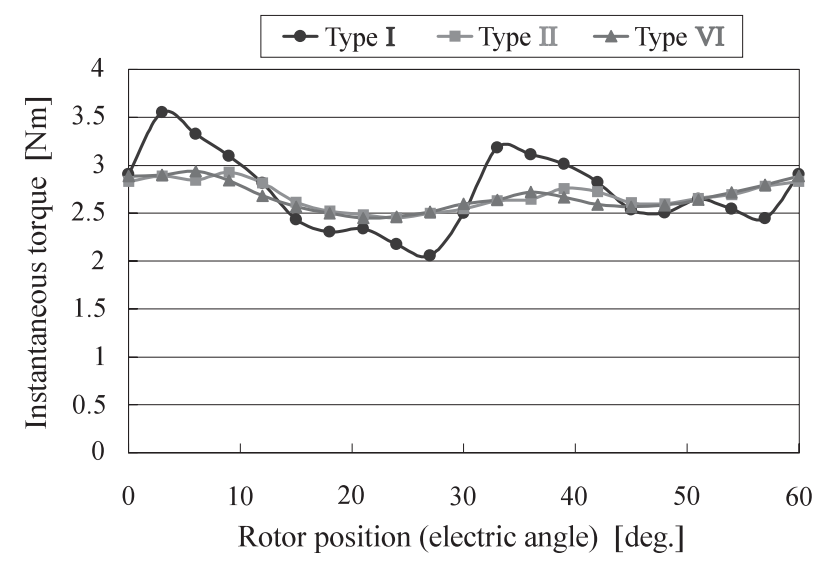

Fig. 15. Instantaneous torque the silicon steel plate, rotating it every 90 degrees. So the minimum lamination unit of Type II is 4 . In Type VI after the lamination like Type II, the silicon steel plate need to be turned upside down and laminate it the same way because all flux barriers are different. So the minimum lamination unit of Type VI is 8. So, Type II is an excellent model in this analysis from the viewpoint of the torque ripple characteristic.

As a result, it turns out that the torque ripple characteristic is significantly improved by using the asymmetrical flux barriers.

\section{Experiment}

The prototype motors of Type A and Type C were manufactured, and the line-to-line induced voltage and the average torque of the prototype motors were measured. The experimental system is shown in Fig. 16 and the photograph of the prototype motor is shown in Fig. 17.

The line-to-line induced voltage waveforms of the prototype motors at the speed of 1,000 $\mathrm{min}^{-1}$ are shown in Fig. 18 and Fig. 19. The line-to-line induced voltage of Type $\mathrm{C}$ is about $30 \%$ larger than that of Type A. Since the induced voltage is proportional to the armature flux linkage due to the permanent magnet $\psi_{a}$, the increase of $\psi_{a}$, which is shown by

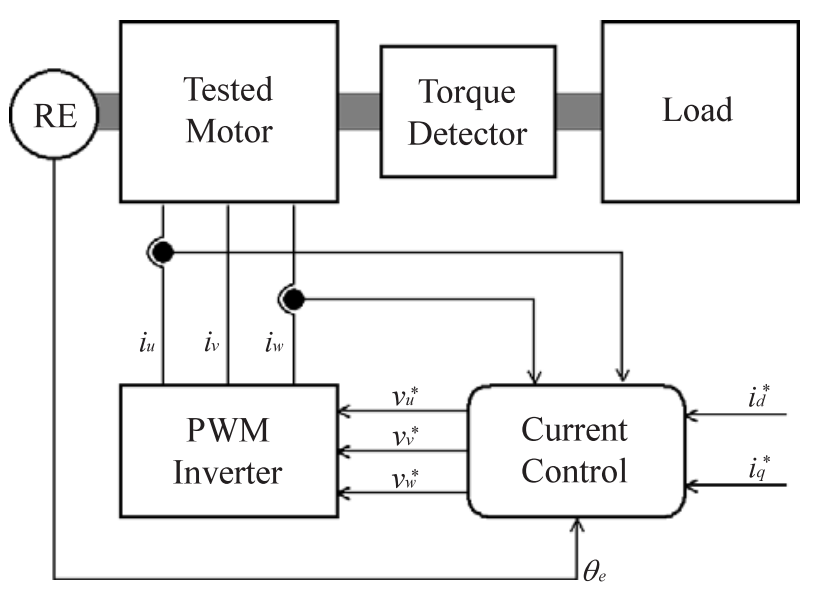

Fig. 16. Experimental system

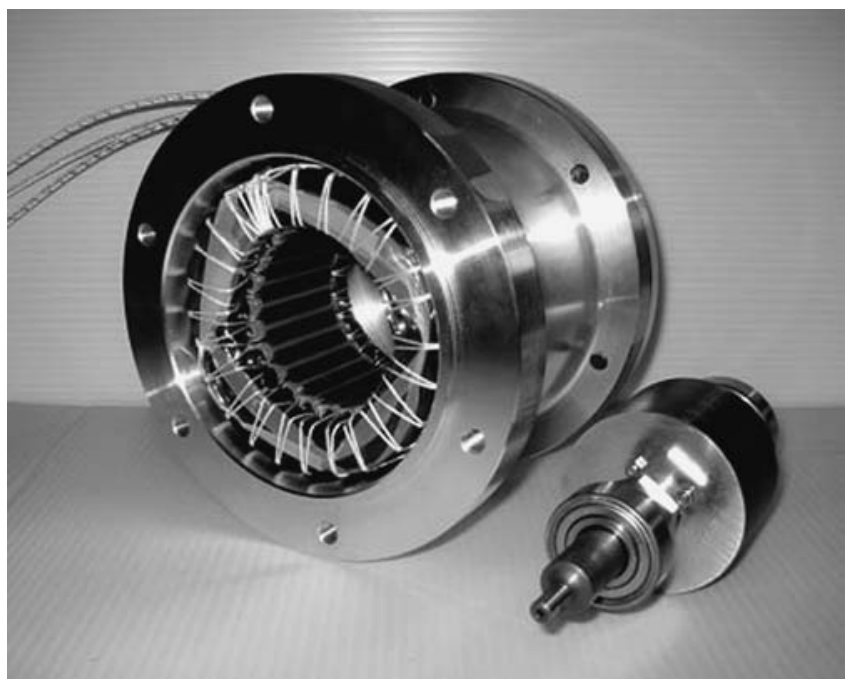

Fig. 17. Photograph of prototype motor 


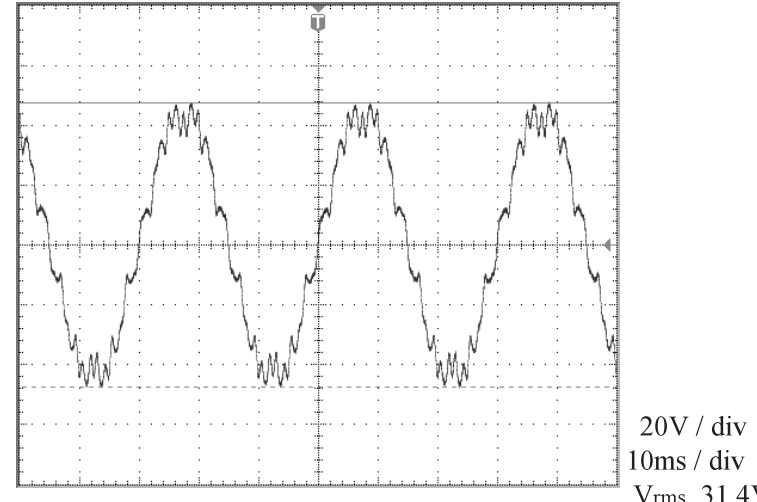

Fig. 18. Induced voltage (Type A)

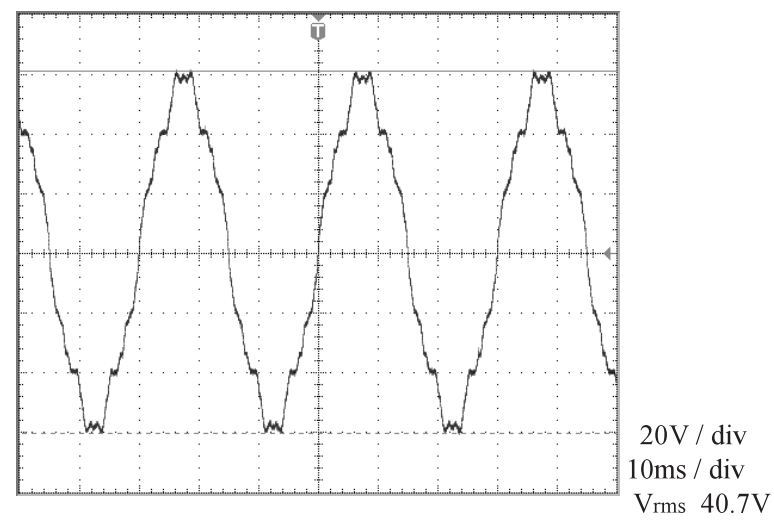

Fig. 19. Induced voltage (Type C)

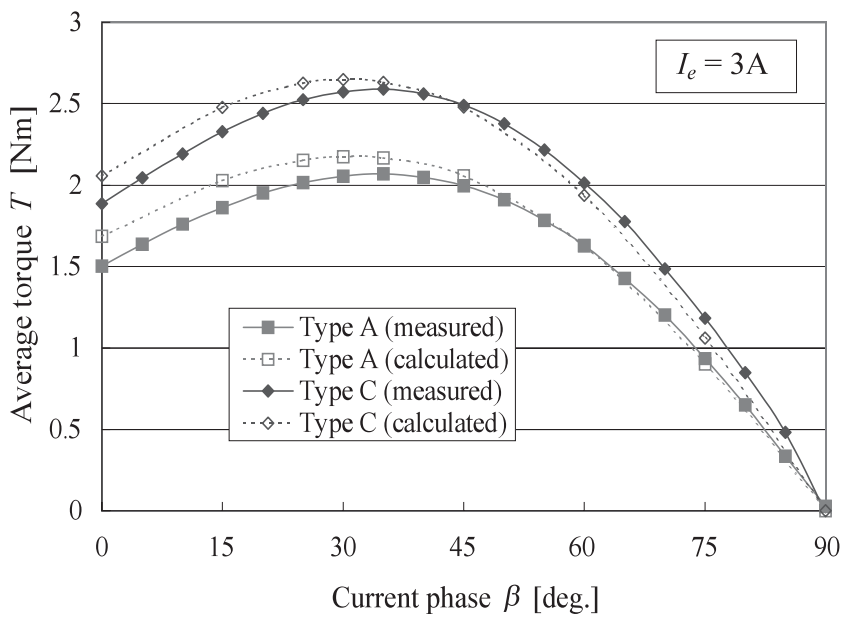

Fig. 20. Experimental average torque

the analysis, is confirmed.

The average torque characteristics of the prototype motors at the speed of $1,000 \mathrm{~min}^{-1}$ are shown in Fig. 20. It is confirmed that the measured torque characteristic and the calculated torque characteristic have the same tendency. The average torque of the proposed rotor structure is about $25 \%$ larger than that of the conventional rotor.

\section{Conclusions}

In this paper the relation between the permanent magnet arrangement and the torque performances for a single-layer
IPMSM using a rare earth permanent magnet was examined. It turns out that the magnet torque increases as the permanent magnets are moved to the surface. This was confirmed in the experiment. The torque increases when the permanent magnet is moved toward the surface because the leakage of the magnetic flux decreases. In addition, the torque ripple is significantly improved when using the asymmetrical flux barriers.

This paper shows that a remarkable characteristic improvement can be made by the optimization of the rotor structure. Using the way stated in this paper, various characteristics are probably improved in not only the single-layer IPMSM but other models.

(Manuscript received May 30, 2005,

revised Jan. 10, 2006)

This paper was presented at IPEC-Niigata 2005, and approved for publication in the IEEJ Transactions on Industry Applications Society.

\section{References}

( 1 ) Z.Q. Zhu and D. Howe: "Influence of design parameters on cogging torque in permanent magnet machines", IEEE Trans. on Energy Conversion, Vol.15, No.4, pp.407-412 (2000-4)

(2) Z.Q. Zhu, S. Ruangsinchaiwanich, N. Schofield, and D. Howe: "Reduction of cogging torque in interior-magnet brushless machines", IEEE Trans. on Magnetics, Vol.39, No.5, pp.3238-3240 (2003-5)

( 3 ) K. Atallah, J. Wang, and D. Howe: "Torque-ripple minimization in modular permanent-magnet brushless machines", IEEE Trans. on Ind. Appl., Vol.39, No.6, pp.1689-1695 (2003-6)

( 4 ) N. Matsumoto, S. Nishimura, M. Sanada, S. Morimoto, and Y. Takeda: "Torque performances and arrangement of permanent magnet for IPMSM", The Papers of Technical Meeting on Rotating Machinery, IEE Japan, RM04-52 (2004) (in Japanese)

( 5 ) K. Hiramoto, Y. Takeda, M. Sanada, and S. Morimoto: "Torque ripple reduction of reluctance torque assisted motors using asymmetric flux barriers", $T$. IEE Japan, Vol.124-D, No.2, pp.208-214 (2004-2) (in Japanese)

( 6 ) M. Sanada, K. Hiramoto, S. Morimoto, and Y. Takeda: "Torque ripple improvement for synchronous reluctance motor using an asymmetric flux barrier arrangement", IEEE Trans. on Ind. Appl., Vol.40, No.4, pp.1076-1082 (2004-4)

Naohisa Matsumoto (Student Member) was born in Japan in 1982.

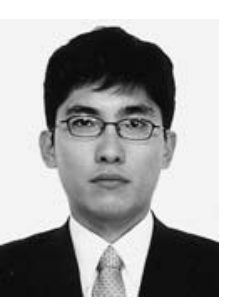
$\mathrm{He}$ is currently a graduate student of Osaka Prefecture University, Sakai, Japan. His main area of research interest is a torque performance improvement of interior permanent magnet synchronous motors.

Masayuki Sanada (Member) was born in Japan in 1966. He received

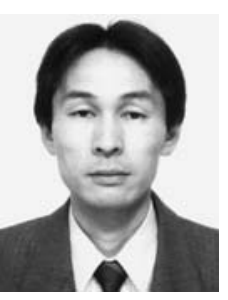
the B.E., M.E., and Ph.D degrees from Osaka Prefecture University, Sakai, Japan, in 1989, 1991, and 1994, respectively. In 1994, he joined the Department of Electrical and Information Systems, Osaka Prefecture University, where he is currently an Assistant Professor. His main areas of research are linear motors for the direct drive applications and their control systems. Dr. Sanada is a Member of the IEEE, the Japan Institute of Power Electronics, and the Japan Society of Applied Electromagnetics and Mechanics. 
Shigeo Morimoto (Member) was born in Japan in 1959. He received

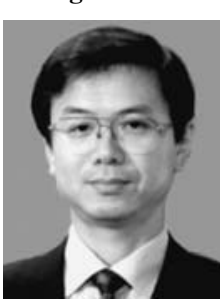
the B.E., M.E., and Ph.D degrees from Osaka Prefecture University, Sakai, Japan, in 1982, 1984, and 1990, respectively. He joined Mitsubishi Electric Corporation, Tokyo, Japan, in 1984. Since 1988, he has been with the Department of Electrical and Information Systems, Osaka Prefecture University, where he is currently an Associate Professor. He has been engaged in research on ac drive systems and motion control. Dr. Morimoto is a Member of the IEEE, the Society of Instrumental and Control Engineers of Japan, the Institute of Systems, Control and Information Engineers, and the Japan Institute of Power Electronics.
Yoji Takeda (Member) was born in Japan in 1943. He received the

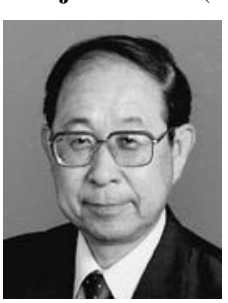
B.E., M.E., and Ph.D degrees from Osaka Prefecture University, Sakai, Japan, in 1966, 1968, and 1977, respectively. Since 1968, he has been with the Department of Electrical and Information Systems, Osaka Prefecture University, where he is currently a Professor. His main areas of research are permanent magnet synchronous motors, linear motors, and their control systems. Dr. Takeda is a Member of the IEEE, the Institute of Systems, Control and Information Engineers, and the Japan Institute of Power Electronics. 